17 Wolpaw TM, Wolpaw DR, Papp KK. SNAPPS: a learner-centred model for outpatient education. Acad Med 2003;78:893-8.

18 Chacko K, Aagaard E, Irby D. Teaching models for outpatient medicine. Clin Teacher 2007;4(2):82-6.

19 Irby D, Bowen J. Time-efficient strategies for learning and performance. Clin Teacher 2004;1(1):23-8.

20 Smith AG, Bromberg MB, Singleton JR, Forshew DA. The use of "clinic room" presentation as an educational tool in the ambulatory care setting. Neurology 1999;52:317-20.

21 Usatine RP, Nguyen K, Randall J, Irby DM. Four exemplary preceptors' strategies for efficient teaching in managed care settings. Acad Med 1997;72:766-9.

22 Hewson M, Little M. Giving feedback in medical education: verification of recommended techniques. J Gen Intern Med 1998 13:111-6.

23 Davis D, Mazmanian P, Fordis M, van Harrison R, Thorpe K, Perrier L. Accuracy of physician self-assessment compared with observed measures of competence: a systematic review. JAMA 2006;296:1094-102.

24 Ruedy J, MacDonald N, MacDougall B. Ten-year experience with mission-based budgeting in the faculty of medicine of Dalhousie University. Acad Med 2003;78:1121-9.

25 Stites S, Vansaghi L, Pingleton S, Cox G, Paolo A. Aligning compensation with education: design and implementation of the educational value unit (EVU) system in an academic internal medicine department. Acad Med 2005;80:1100-6.

26 Watson R, Romrell L. Mission-based budgeting: removing a graveyard. Acad Med 1999;74:627-40.

27 Irby D, Cooke M, Lowenstein D, Richards B. The academy movement: a structural approach to reinvigorating the educational mission. Acad Med 2004;79:729-36.

28 Simpson D, Fincher R, Hafler J, Irby D, Richards B, Rosenfeld G, et al. Advancing educators and education by defining the components and evidence associated with educational scholarship. Med Educ 2007;41:1002-9.

\title{
RATIONAL IMAGING
}

\section{Investigating perianal pain of uncertain cause}

\author{
Rebecca Greenhalgh, ${ }^{1}$ C Richard Cohen, ${ }^{1}$ David Burling, ${ }^{2}$ Stuart Andrew Taylor ${ }^{1,3}$
}

'University College Hospital, London NW1 2BU

${ }^{2}$ St Mark's Hospital, Harrow HA1 3UJ

${ }^{3}$ University College London,

London

Correspondence to: S A Taylor

stuart.taylor@uclh.nhs.uk

BMJ 2008;336:387-9

doi:10.1136/bmj.39455.393299.AD
This series provides an update on the best use of different imaging methods for common or importan clinical presentations. The series advisers are Fergus Gleeson, consultant radiologist, Churchill Hospital, Oxford, and Kamini Patel, consultant radiologist, Homerton University Hospital, London.

\section{This article explores the radiological investigations available to diagnose perianal pain of unknown cause, with particular reference to perianal sepsis}

\section{The patient}

A 29 year old woman presented with constipation, constant perianal burning, and pain on defecation. Digital rectal examination was uncomfortable with induration in the right posterior quadrant, but there was no evidence of anal fissure or skin tag, thrombosed haemorrhoid, perianal haematoma, anal mass, or palpable abscess or fistula. Perianal skin sensation was normal.

\section{What is the next investigation?}

The aim of further investigation is to identify those causes of perianal pain not always detected by direct clinical examination. Commoner causes to consider include occult perianal sepsis such as intersphincteric abscess (the prevalence of anal fistula in the general population is about $0.01 \%{ }^{1}$ ), anal complications of inflammatory bowel disease, and anal cancer. Rarer causes include retrorectal developmental cysts, sacrospinal tumours, and sacral nerve tumours. Proctalgia fugax (intermittent severe anal or lower rectal pain of unknown aetiology) remains a diagnosis of exclusion.

\section{Anal endosonography}

Anal endosonography is a quick, safe, and cheap technique but requires operator experience. It provides detailed, high resolution images of the anal sphincter complex and intersphincteric space. Although its main clinical role is in investigating faecal incontinence, anal endosonography will usually reveal the presence of occult intersphincteric abscesses. It may also show anal tumours and developmental cysts, particularly if they communicate with the intersphincteric space, but data on its accuracy for these rarer conditions are limited.

Advantages and disadvantages of the use of anal endosonography and magnetic resonance imaging in the investigation of perianal pain of uncertain cause

\begin{tabular}{|c|c|}
\hline Anal endosonography & Magnetic resonance imaging \\
\hline No ionising radiation & No ionising radiation \\
\hline High resolution images of anal sphincter complex & Good resolution of anal sphincter complex \\
\hline $\begin{array}{l}\text { Small field of view limits evaluation of tissues and disease } \\
\text { processes extending beyond anal canal }\end{array}$ & $\begin{array}{l}\text { Large field of view allows evaluation of tissues and disease processes extending beyond } \\
\text { anal canal }\end{array}$ \\
\hline Examination time around 5 minutes & Examination time around 20 minutes \\
\hline No reported patient safety issues ${ }^{3}$ & $\begin{array}{l}\text { Contraindicated in patients with certain metal implants; relatively contraindicated in first } \\
\text { trimester of pregnancy }{ }^{4} \text {; claustrophobia can prevent scanning }\end{array}$ \\
\hline Operator dependent & Standardised scanning protocol \\
\hline Requires specialised ultrasound equipment & Requires standard MRI scanner only \\
\hline Requires insertion of endoanal probe & Can be performed without insertion of endoanal coil \\
\hline
\end{tabular}

All statements are supported by evidence, but references are supplied only for the less well established statements. 
In the case of perianal sepsis, an abscess is usually seen as a rounded, low echogenic defect between the internal and external anal sphincter, whereas the primary track of an established anal fistula is seen as a hypoechoic band (fig 1). In a non-randomised study of preoperative imaging in patients with suspected perianal sepsis, anal endosonography had $82 \%$ sensitivity for the correct classification of simple primary perianal fistulas. $^{2}$

However the technique is limited by its relatively small field of view (just a few centimetres), such that
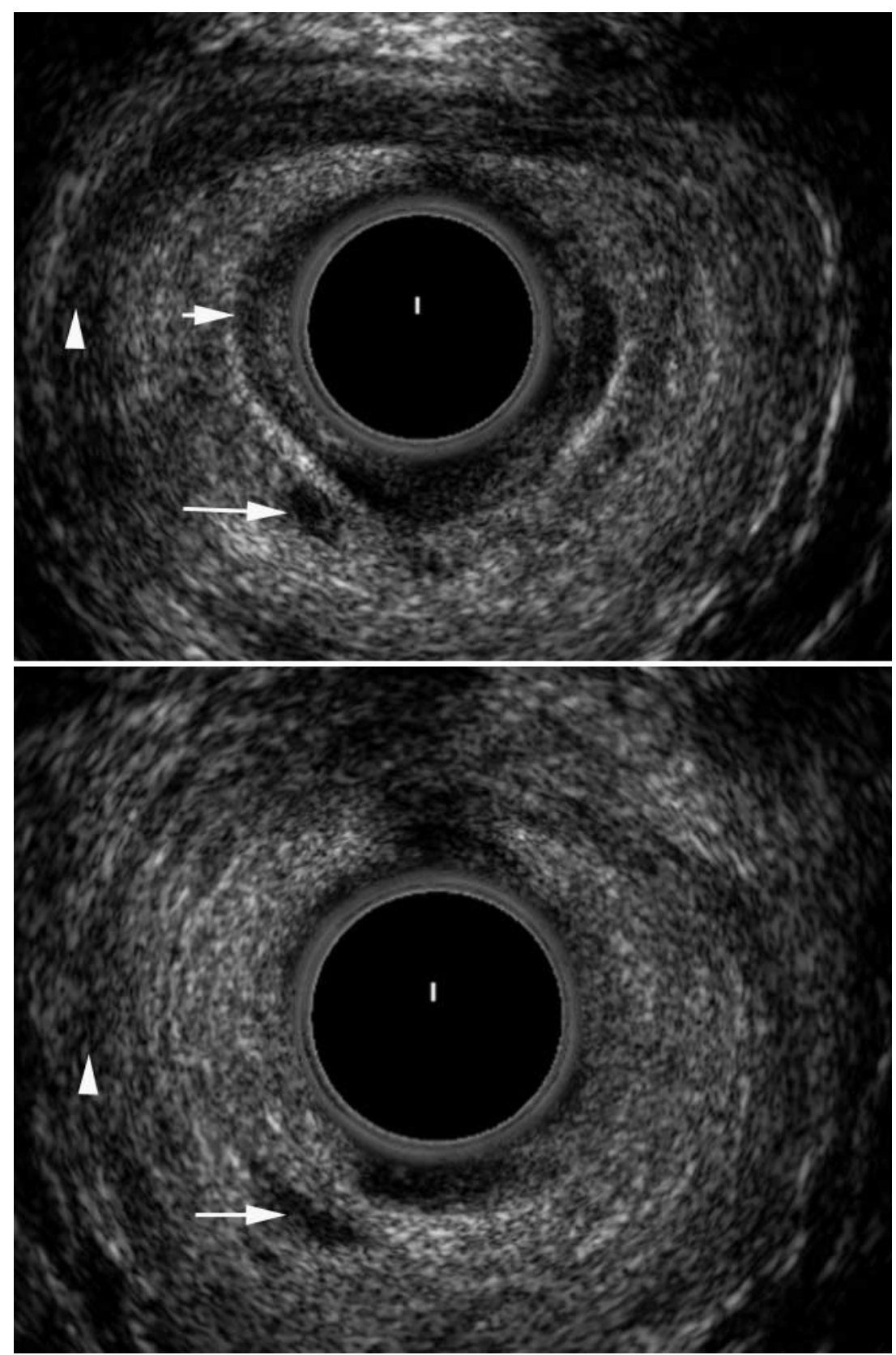

Fig 1 Results of anal endosonography. Top: image of the distal anal canal, showing an intersphincteric abscess (long arrow) as a local, low echogenic focus between the internal sphincter (short arrow) and external sphincter (arrowhead). Bottom: image distal to terminal fibres of the internal anal sphincter shows a low echogenic track (arrow) medial to the distal fibres of the external anal sphincter (arrowhead) in keeping with an intersphincteric fistula structures lateral to or above the anal sphincter complex are poorly visualised. For example, the presacral space, sacrum, and perirectal tissues are not reliably assessed, so sacrospinous tumours and pathological processes above the pelvic floor are not reliably excluded.

\section{Magnetic resonance imaging (MRI)}

MRI provides high contrast and high resolution images of soft tissue, allowing exquisite depiction of the anal canal structures and surrounding tissues. Although generally a safe technique, it is more time consuming than anal endosonography, is best avoided in early pregnancy, and is contraindicated in some patients with implanted metallic devices including cardiac pacemakers (table). ${ }^{45}$ Spatial resolution can be improved by placing a receiver endocoil in the anal canal itself, ${ }^{6}$ although in a comparative study of 30 patients an external MRI receiver coil placed over the pelvis was better tolerated than an endocoil and provided additional diagnostic information beyond the anal canal. ${ }^{7} \mathrm{MRI}$ affords much greater anatomical coverage than anal endosonography and can show the perirectal tissues and sacrolumbar spine, thereby facilitating diagnosis of developmental cysts, sacrospinal tumours, and sacral nerve tumours.

In the case of suspected perianal sepsis, abscesses and fistulous tracks are seen as areas of bright high signal against the lower signal anatomical structures (fig 2). One major advantage of MRI over anal endosonography is its ability to delineate secondary extensions and abscesses arising from the primary fistulous track, which often course beyond the ultrasonic field of view. Such extensions, if unrecognised, are responsible for most cases of fistula recurrence after surgical treatment. In one study MRI detected $90 \%$ of primary tracks and was superior to anal endosonography in the detection of secondary abscesses remote from the primary fistula $(85 \% v 75 \%) .{ }^{2}$ In a nonrandomised study of imaging in patients with recurrent anal fistula, use of preoperative MRI to guide surgery reduced future recurrence by $75 \%$ compared with standard surgery. ${ }^{8}$

\section{Examination under anaesthetic}

For patients who cannot tolerate digital rectal examination when awake, examination under anaesthetic is essential so that local causes of anal pain such as fissure or thrombosed haemorrhoids can be excluded. The procedure itself is well tolerated, but general anaesthesia carries a small risk. In patients with suspected perianal sepsis, examination may reveal the internal opening, secondary tracks, and abscesses, although in one study even experienced staff were able to identify only $61 \%$ of primary tracks, $78 \%$ of internal openings, and $33 \%$ of abscesses. ${ }^{2}$ The combination of normal results from examination under anaesthetic and from MRI allows a diagnosis of proctalgia fugax to be made with greater certainty. 


\section{Outcome}

Given the patient's relatively acute history and the findings from digital rectal examination, occult perianal sepsis was suspected. Anal endosonography, being quick and readily available, was performed on the same day as the outpatient assessment and confirmed a small intersphincteric abscess, probably associated with an intersphincteric fistula (fig 1).

Further imaging would not usually be indicated for a simple perianal abscess or fistula before surgical treatment, but there was clinical concern that the palpable induration in the anal canal could indicate
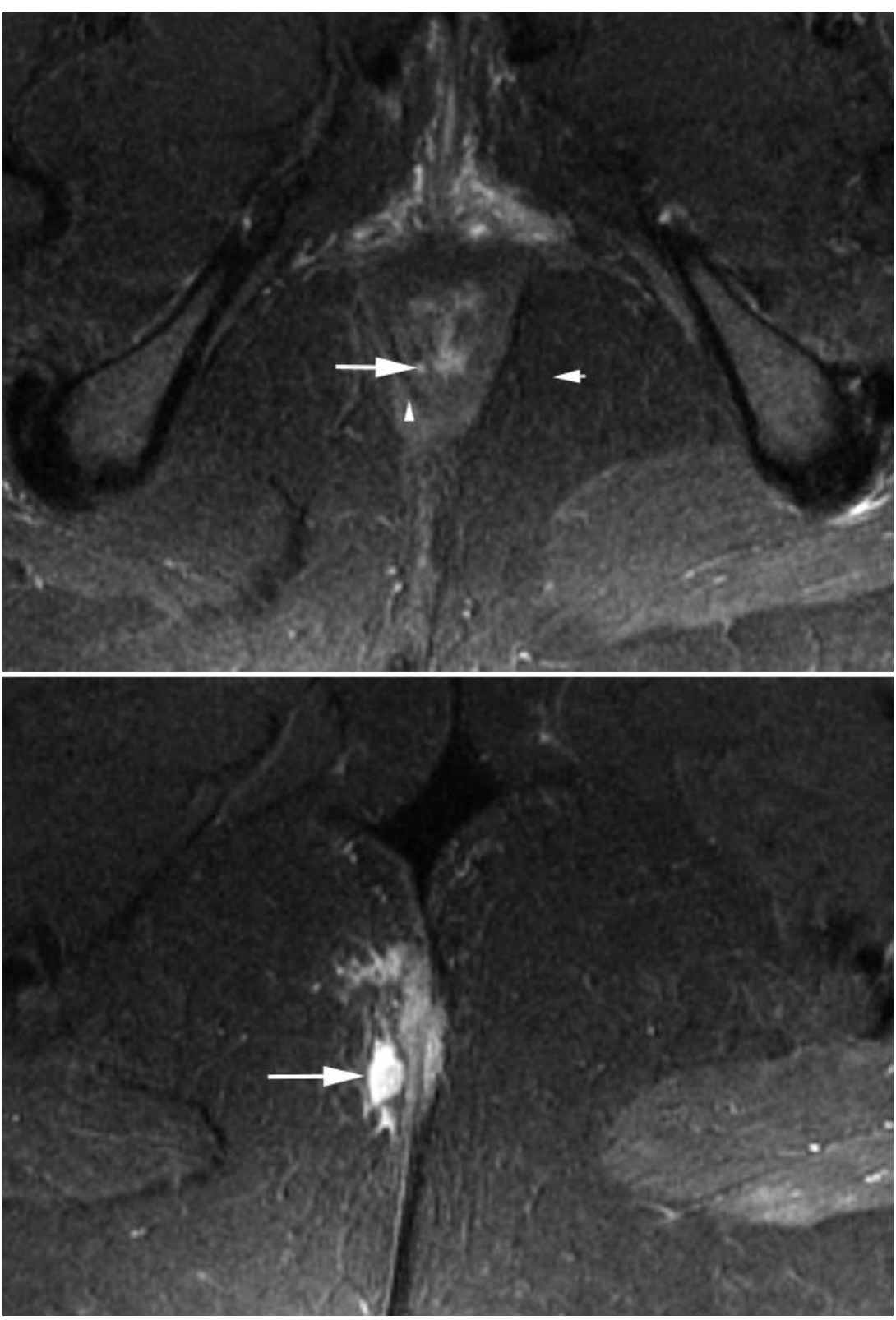

Fig 2 Results of axial magnetic resonance imaging. Top: section through the distal anal canal shows the internal opening of the fistula (long arrow) as a high signal focus at the 7 o'clock position; there is no evidence of sepsis beyond the external sphincter (arrowhead) in the ischioanal fossa (short arrow). Bottom: section distal to the anal sphincters shows the fistulous track (arrow) as high signal and forming a small abscess

\section{LEARNING POINTS}

Imaging plays an important role in elucidating the cause of anal pain when the diagnosis is not clinically apparent

Endoanal ultrasound is an increasingly available, relatively inexpensive, quick and safe technique providing high resolution images of the anal sphincter complex, and intersphincteric space, but it is limited by a relatively small field of view

Magnetic resonance imaging, although not universally available, affords much greater anatomical coverage than endoanal ultrasound and can also image the perirectal tissues and lumbar-sacral spine, facilitating diagnosis of conditions beyond the anal canal

In the case of perianal sepsis, preoperative magnetic resonance imaging may be indicated in clinically suspected complex or recurrent disease to guide surgery, reducing the risk of future recurrence

extension of sepsis beyond the primary abscess. Given the known risk of fistula recurrence caused by undiagnosed (and thus untreated) extensions, MRI was performed. This confirmed an intersphincteric fistula complicated by a small intersphincteric abscess, but excluded any secondary tracks or extensions (fig 2). The patient then underwent examination under anaesthetic with definitive laying open of fistula and is now symptom-free.

Contributors: RG was responsible for the literature search, obtaining patient consent, collection and preparation of images, drafting the initial manuscript, and approving the final manuscript. CRC was responsible for the literature search, planning and drafting the initial manuscript, and approving the final manuscript. DB was responsible for the full literature search (using evidence based techniques), editing the manuscript, and approving the final manuscript. SAT was responsible for the clinical studies, the literature search, planning and drafting the initial manuscript, and editing and approving the final manuscript. SAT is also guarantor for the article.

Competing interests: None declared

Provenance and peer review: Commissioned; externally peer reviewed.

1 Sainio P. Fistula-in-ano in a defined population. Incidence and epidemiological aspects. Ann Chir Gynaecol 1984;73:219-24.

2 Buchanan GN, Halligan S, Bartram Cl, Williams AB, Tarroni D, Cohen CR. Clinical examination, endosonography, and MR imaging in preoperative assessment of fistula in ano: comparison with outcomebased reference standard. Radiology 2004;233:674-81.

3 Nyborg WL. Safety of medical diagnostic ultrasound. Semin Ultrasound CT MR 2002;23:377-86.

4 International Non-Ionizing Radiation Committee of the International Radiation Protection Association. Protection of the patient undergoing a magnetic resonance examination. Health Phys 1991;61:923-8.

5 International Commission on Non-Ionizing Radiation Protection. Medical magnetic resonance (MR) procedures: protection of patients. Health Phys 2004;87:197-216.

6 DeSouza NM, Gilderdale DJ, Coutts GA, Puni R, Steiner RE. MRI of fistula-in-ano: a comparison of endoanal coil with external phased array coil techniques. J Comput Assist Tomogr 1998;22:357-63.

7 Halligan S, Bartram Cl. MR imaging of fistula in ano: are endoanal coils the gold standard? AJR Am J Roentgenol 1998;171:407-12.

8 Buchanan G, Halligan S, Williams A, Cohen CR, Tarroni D, Phillips RK, et al. Effect of MRI on clinical outcome of recurrent fistula-in-ano. Lancet 2002;360:1661-2.

Accepted: 15 October 2007 